Rev. Elet. em Gestão, Educação e Tecnologia Ambiental (e-ISSN: 2236-1170)

\title{
ANÁLISE DA VARIAÇÃO HIGROTÉRMICA OCASIONADA PELA INFLUÊNCIA DA OCUPAÇÃO DO SOLO NA CIDADE DE CUIABÁ-MT
}

\author{
Flávia Maria de Moura Santos \\ Professora do Departamento de Arquitetura e Urbanismo/ FAET/ UFMT, Doutora em Física Ambiental, Linha de \\ Pesquisa: Análise Microclimática em Sistemas Urbanos, E-mail: flavia_mms@hotmail.com

\section{Carlo Ralph de Musis} \\ Professor da Universidade de Cuiabá/ UNIC, Professor do Programa de Pós-Graduação em Física Ambiental, \\ Linha de Pesquisa: Análise Microclimática em Sistemas Urbanos, E-mail: carlo.demusis@gmail.com

\section{José de Souza Nogueira} \\ Professor do Departamento de Física/ IF/ UFMT e Coordenador do Programa de Pós-Graduação em Física \\ Ambiental, E-mail: nogueira@ufmt.br

\section{Osvaldo Borges Pinto Júnior} \\ Professor da Universidade de Cuiabá/ UNIC, Professor do Programa de Pós-Graduação em Física Ambiental, \\ Linha de Pesquisa: Análise Microclimática em Sistemas Urbanos, E-mail: osvaldo.borges@gmail.com
}

\section{Marta Cristina de Jesus Albuquerque Nogueira}

Professora do Departamento de Arquitetura e Urbanismo/ FAET/ UFMT, Professora do Programa de Pós-Graduação em Física Ambiental, Linha de pesquisa: Análise Microclimática em Sistemas Urbanos, E-mail: mcjanp@gmail.com

\section{http://dx.doi.org/10.5902/223611707699}

\section{RESUMO:}

Os fatores que se processam sobre a camada de limite urbana acabam criando um clima próprio em aglomerados urbanos que associados aos tipos e graus de adensamento e uso do solo têm a capacidade de modificar os elementos climáticos que compõem a atmosfera local. Desta forma, esta pesquisa teve como objetivo identificar as diferenças higrotérmicas intraurbana de Cuiabá-MT-Brasil, por transectos móveis noturno nas quatro estações do ano utilizando-se termohigrômetro digital, protegido por abrigo, acoplado na lateral de um veículo que saiu da periferia (rural), chegando ao extremo oposto da cidade, nos sentidos Leste-Oeste e Norte-Sul. Destaca-se que áreas sob influência de massas de vegetação, apresentaram microclima diferentes às outras áreas da cidade, pois há uma contribuição na perda de energia para o meio e conseqüente diminuição nos valores de temperatura do ar e aumento da umidade relativa do ar, evidenciando-se a importância da implantação de parques em locais de clima rigoroso como em Cuiabá.

Palavras-chave: Ocupação do solo, vegetação, microclima.

\section{ANALYSIS OF VARIATION HYGROTHERMAL ARISING BY INFLUENCE OF OCCUPATION OF LAND IN THE CITY CUIABÁ-MT}

\section{ABSTRACT:}

The factors that are processed on the urban boundary layer eventually creating a climate of its own in urban areas that related to types and degrees of density and land use have the ability to change the climate elements that make up the local atmosphere. Therefore, this study aimed to 
Rev. Elet. em Gestão, Educação e Tecnologia Ambiental (e-ISSN: 2236-1170)

identify differences hygrothermal intraurbana Cuiaba-MT, Brazil, for mobile transects night in four seasons using digital hygrometer, protected shelter, attached to the side of a vehicle that left the periphery (rural), arriving at the opposite end of town, in the directions East-West and NorthSouth. It is noteworthy that areas under the influence of masses of vegetation, microclimate showed different to other areas of the city because there is a contribution to the energy loss to the environment and consequent decrease in values of air temperature and increased relative humidity, showing the importance of implementing parks in places like harsh climate in Cuiaba.

Keywords: Land cover, vegetation, microclimate.

\section{INTRODUÇÃO}

As cidades podem ser entendidas como organizações estritamente humanas, nas quais o homem atua com toda a sua força e plenitude, transformando a natureza em função de suas necessidades. Os grandes aglomerados urbanos acabam criando um verdadeiro clima urbano gerado através da interferência dos fatores que se processam sobre a camada de limite urbana e que agem alterando o clima em escala local. Cria-se então anomalias na temperatura e na umidade, sendo as ilhas de calor urbana (ICU) o fenômeno mais representativo dessas modificações (ALVES, 2010).

O fenômeno ilha de calor é formado através das diferenças do balanço de energia entre a cidade e o campo, sendo uma anomalia térmica, com dimensões horizontais, verticais e temporais. Suas características estão relacionadas com a natureza da cidade (tamanho, densidade de construções, uso do solo) e com as influências externas (clima, tempo e estações) (OKE, 1982). Há várias causas que originam as ilhas de calor e dentre elas destacam-se: o armazenamento de calor durante o dia na cidade, oriundas das propriedades térmicas e caloríficas dos materiais de construções e sua devolução para a atmosfera durante a noite; a produção do calor antropogênico (circulação de veículos e pessoas); a diminuição da evaporação decorrente da substituição da superfície original por concreto e asfalto e a canalização fechada de rios e córregos e a menor perda de calor sensível, devido à redução da velocidade do vento originada pelas edificações.

A percepção e identificação da máxima intensidade da ilha de calor são observadas sob condições de tempo atmosférico ideal: céu claro e ventos fracos. Horizontalmente há diminuição da temperatura do ar e aumento da umidade relativa à medida que há a aproximação com o campo. As cidades têm uma atmosfera mais instável o que ocasiona diminuição na velocidade do vento em relação ao campo. Assim a tendência do ar, sob condições atmosféricas estáveis, é circular do campo: menos quente, alta pressão - em direção ao centro; mais quente, baixa pressão (AMORIM, 2000).

A relevância de estudos desta natureza está em viabilizar maior conhecimento sobre as características urbanas principalmente no que se refere às mudanças térmicas associadas ao uso e a ocupação do solo. As características urbanas associadas aos tipos e graus de adensamento e uso que recobrem o solo têm a capacidade de modificar os elementos climáticos que compõem a atmosfera local. O tipo de uso e ocupação do solo pode ainda ter seu efeito maximizado de acordo com o relevo existente no sítio urbano (ARAÚJO et al., 2008).

Neste sentido, como afirmam Monteiro \& Mendonça (2003), é necessário adentrar a cidade e identificar os aspectos dos diferentes dinamismos da vida urbana, como: tráfego de veículos automotores, concentração de aparelhos de ar condicionado, remoção da cobertura vegetal, canalização de córregos, adensamento de construções. 
Desta forma, o trabalho teve com objetivo a identificação das diferenças de temperatura e umidade intraurbana de Cuiabá-MT, em áreas com ocupações do solo diferenciadas, por meio de transectos móveis noturno.

\section{2 ÁREA DE ESTUDO}

Este estudo foi desenvolvido no município de Cuiabá-Brasil, que está situado entre as coordenadas geográficas de 1510', 1550' de latitude sul e 5050', 5010' de longitude oeste, na região central do Brasil. Possui uma área de $3.538,17 \mathrm{Km}^{2}$, correspondendo $254,57 \mathrm{Km}^{2}$ à macrozona urbana e $3.283,60 \mathrm{Km}^{2}$ à área rural. Além do distrito-sede de Cuiabá, integram o município os distritos Coxipó da Ponte, Coxipó do Ouro e Guia, Figura 01, (CUIABÁ, 2009).

O clima da cidade é do tipo Aw de Koppen, classificado como Tropical semi-úmido, com quatro a cinco meses secos (maio a setembro) e máximas diárias de temperatura que oscilam entre $30^{\circ} \mathrm{C}$ e $36^{\circ} \mathrm{C}$, apresentando duas estações bem definidas, uma seca (outono-inverno) e uma chuvosa (primavera-verão).

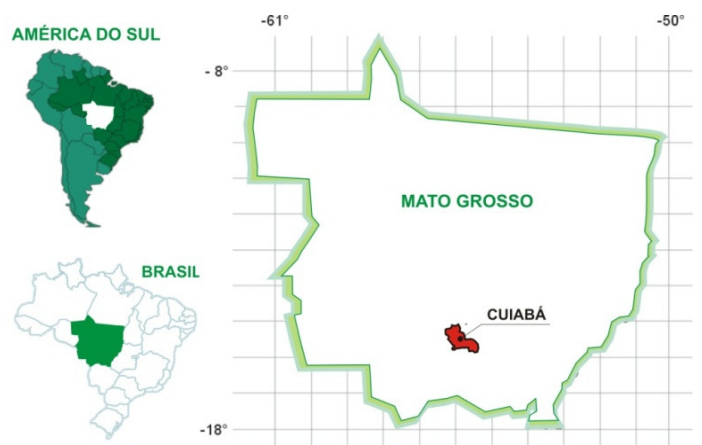

Figura 01 - Localização do município de Cuiabá Fonte: Oliveira, (2011)

Com clima Tropical Continental, sem influência marítima, onde já foi detectada a interferência do uso do solo urbano na ocorrência de ilhas de calor, Cuiabá apresenta baixa freqüência e velocidade média dos ventos, que torna a influência do espaço construído sobre a temperatura do ar mais perceptível, já que as trocas térmicas por convecção são minimizadas (MAITELLI, 1994).

\section{MÉTODO}

A metodologia para o registro da temperatura do ar e umidade relativa do ar consistiu na definição de dois transectos, com coletas móveis ao longo do transecto e em pontos préestabelecidos com diferentes ocupações do solo, utilizando-se um Datalogger digital de temperatura e umidade do ar da marca Instrutherm, modelo HT-500, com leitura a cada 10 segundos, protegido por abrigo, acoplado na lateral de um veículo a altura aproximada de 2,00m do solo e distante $0,50 \mathrm{~m}$ do automóvel. O trajeto consistia em sair da periferia (rural), passando pelo centro e chegando ao extremo oposto da cidade, em dois sentidos: leste/oeste - 1a (início) /1b (término) e norte/sul - 2a (início) /2b (término) (Figura 02). Apenas o ponto inicial do Transecto 2 (2a) encontra-se em área com características de área central, devido a proximidade do centro da cidade e do município vizinho - Várzea Grande.

A coleta de dados com veículo requer que o tempo gasto entre a medida do ponto inicial e no ponto final do itinerário não ultrapasse uma hora, com velocidade que deve variar entre $30 \mathrm{e}$ $40 \mathrm{Km} / \mathrm{h}$ (ARAÚJO et al., 2008). 


\section{Figura 02 - Transecto 1a/1b - sentido Leste/Oeste e Transecto 2a/2b - sentido Norte/Sul}

As medições foram efetuadas no período de abril de 2011 a março de 2012 em dias com condições de tempo atmosférico ideal, ou seja, céu claro e ventos fracos (OKE,1982) em todas as estações do ano (Tabela 01). Foram realizadas a partir das 20h para o Transecto 1 e $21 \mathrm{~h}$ para o Transecto 2, horário que as temperaturas não experimentam mudanças rápidas pela ausência da radiação solar, justamente pela diferença de tempo entre a primeira e a última medida. Além disso, é após o pôr do sol que a ICU atinge a intensidade máxima (OKE,1982).

\begin{tabular}{c|c|c}
\multicolumn{2}{c}{ Tabela 01 - Período de medição por transectos móveis } \\
\hline MÊS & DIA & ESTAÇÃO \\
\hline ABRIL/2011 & $12 / 19 / 26$ & outono \\
\hline MAIO/2011 & $09 / 17 / 26$ & outono \\
\hline JUNHO/2011 & $14 / 16 / 21 / 28$ & outono / inverno \\
\hline JULHO/2011 & $07 / 12 / 21 / 26$ & inverno \\
\hline AGOSTO/2011 & $08 / 16 / 29 / 30$ & inverno \\
\hline SETEMBRO/2011 & $06 / 19 / 25 / 28$ & $\begin{array}{l}\text { inverno / } \\
\text { primavera }\end{array}$ \\
\hline OUTUBRO/2011 & 24 & primavera \\
\hline NOVEMBRO/2011 & $09 / 23$ & primavera \\
\hline FEVEREIRO/2012 & 28 & verão \\
\hline MARÇO/2012 & $18 / 19$ & verão \\
\hline
\end{tabular}

Primeiramente era realizado o transecto no sentido leste/oeste $-1 \mathrm{a} / 1 \mathrm{~b}$ com 10 pontos fixos (Figura 03a), posteriormente, o transecto no sentido norte/sul - 2a/2b com 09 pontos fixos (Figura 03b). 


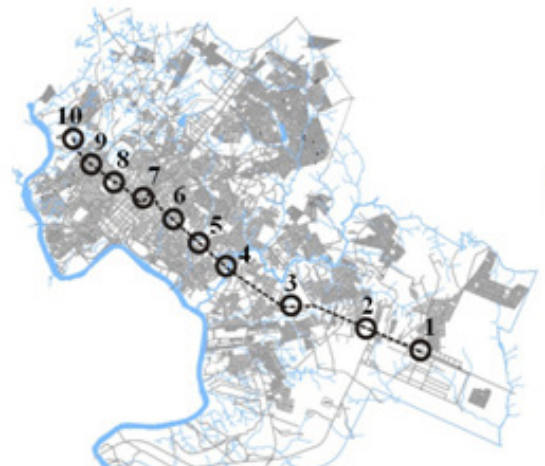

(a)

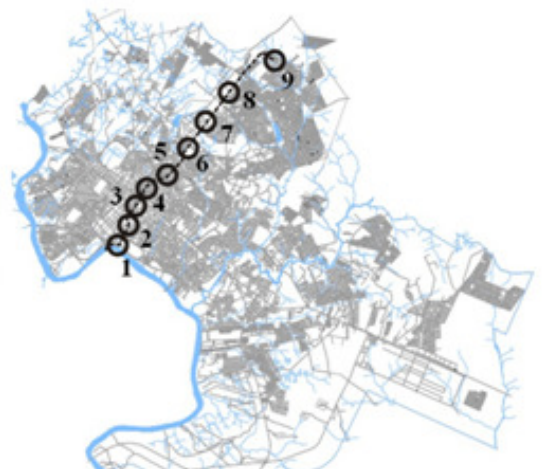

(b)

Figura 03 - Pontos fixos de medição - sentido Leste/Oeste - Transecto 1(a) e sentido Norte/Sul Transecto 2 (b)

Como forma de classificação dos pontos fixos, foi feito o cálculo da área verde em porcentagem em um raio de $200 \mathrm{~m}$ de influência em cada ponto, utilizou-se um software do tipo CAD (computer aided design - desenho auxiliado por computador) com auxílio das imagens no software GoogleEarth.

1

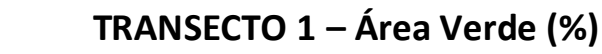

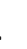

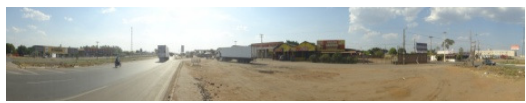

$16,02 \%$

2

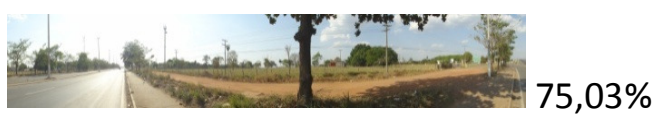

3

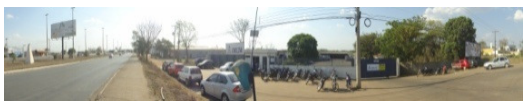

$39,14 \%$

4
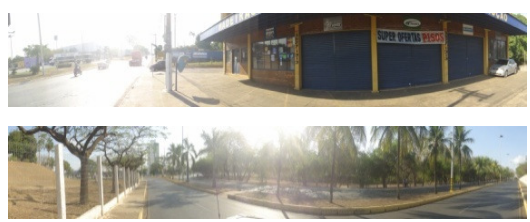

$61,06 \%$

5

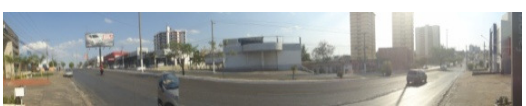

$42,00 \%$

\section{6}

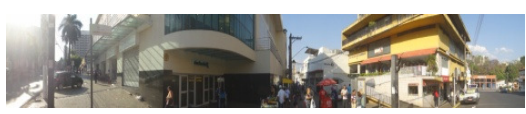

$22,12 \%$

\section{7}

8

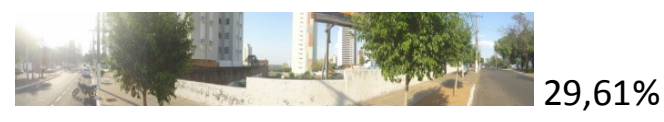

TRANSECTO 2 - Área Verde (\%)

1

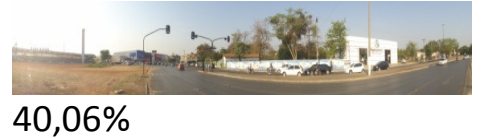

2

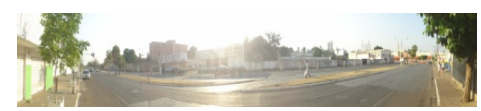

3

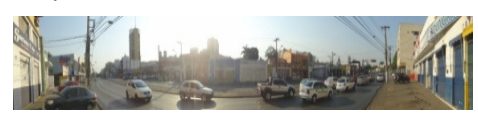

4 $26,64 \%$

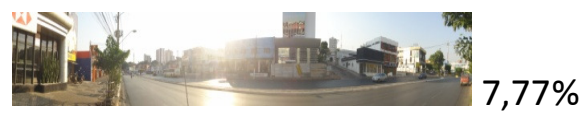

5

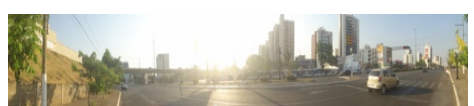

$13,85 \%$

6

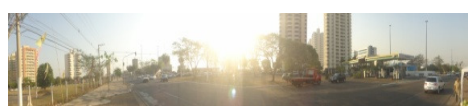

$18,17 \%$

7

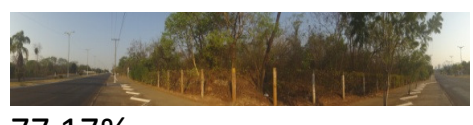

8

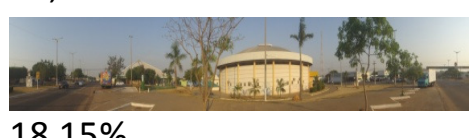

$18,15 \%$ 
9

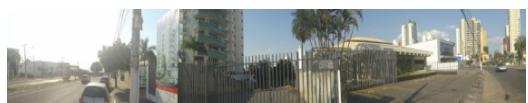

$16,61 \%$

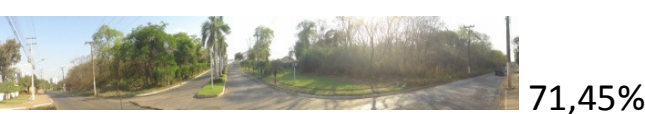

9

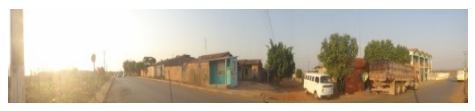

$53,37 \%$

Figura 04 - Pontos fixos de medição e porcentagem área verde - Transecto 1 e Transecto 2

Para comparação dos dados, foi feita correção horária a partir de uma estação microclimática da marca Davis Instruments, modelo Vantage Pro 2 Plus localizada em área densamente urbanizada da cidade (Figura 05) registrando-se regularmente temperatura e umidade relativa do ar, velocidade e direção do vento com intervalo de registro de dados programado para 15 minutos nas $24 \mathrm{~h}$ de cada dia.
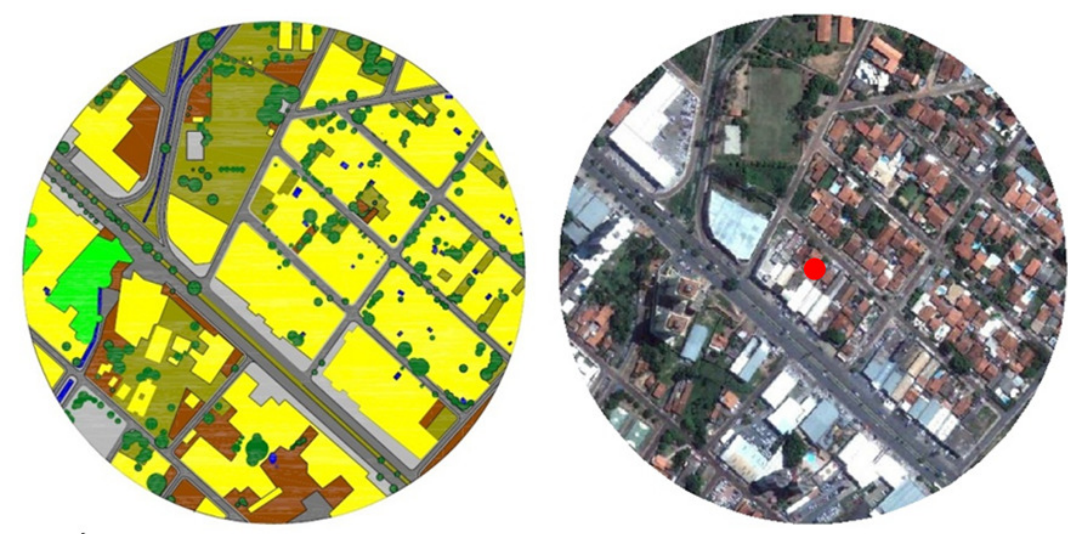

Figura 05 - Área de análise das variáveis micrometeorológica com característica de ocupação urbana

Os dados do dois transectos foram corrigidos para 20h, utilizando-se a fórmula de regressão linear com dados da estação microclimática, para cada dia de medição, fazendo-se a correção dos dados, para posterior análise.

\section{RESULTADOS E DISCUSSÕES}

\subsection{Transecto 1}

Na estação da Primavera observa-se maior magnitude da ilha de calor na cidade (Figura 06), apresentando a mesma tendência na variação de temperatura ao longo do Transecto 1 nas demais estações. As maiores temperaturas encontradas estão entre os pontos 6 (P6T1) e 8 (P8T1) justificado pela ocupação do solo por conta do uso de revestimentos que absorvem energia durante o dia, liberando-as a noite. 


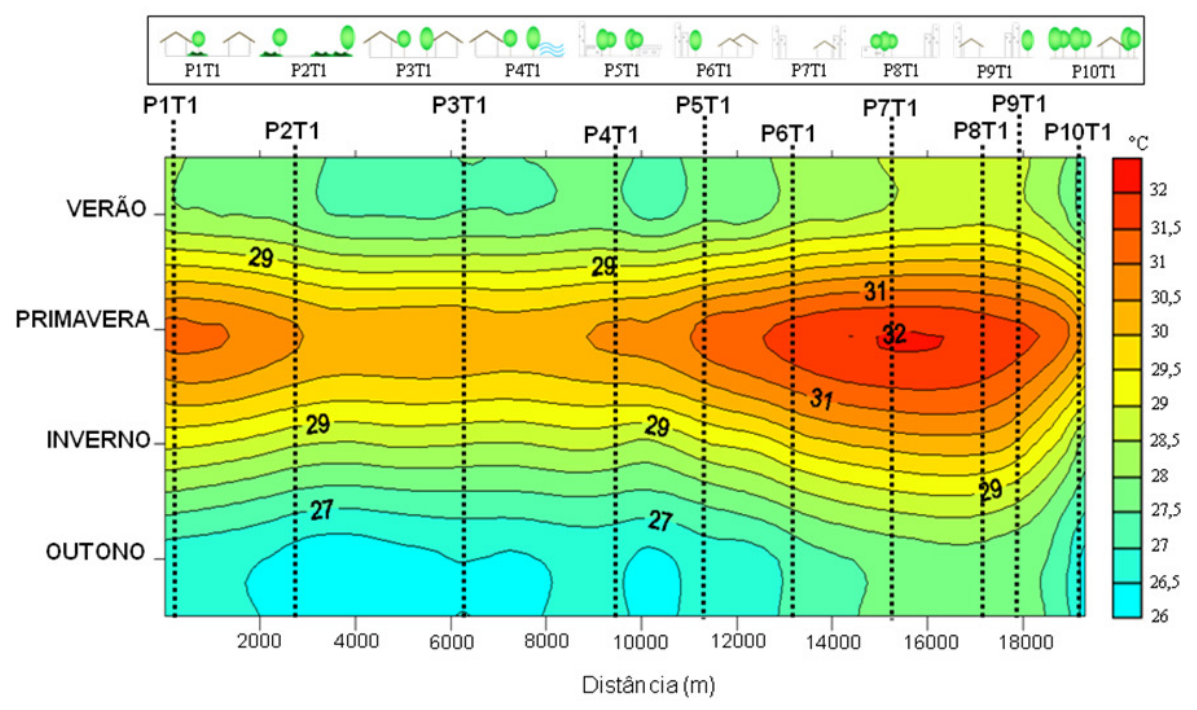

Figura 06 - Comportamento da Temperatura do Ar - Transecto 1

Observa-se que o P8T1 (Tabela 02) é o local que apresenta os índices mais altos de temperatura na maioria das estações do ano, sendo que apenas na Primavera o P7T1 é o ponto com maior temperatura. Os pontos apresentam características urbanas consolidadas, com alta densidade de ocupação, sendo o P7T1 o ponto mais central da cidade, com a concentração da área comercial e consequentemente baixo tráfego de veículos no horário de medição, razão esta que pode ter sido o fator principal das altas temperaturas no P8T1 que caracteriza-se pela área menos impermabilizada mas com alto fluxo de veículos.

Tabela 02 - Temperatura Máxima e Mínima no Transecto 1

\begin{tabular}{c|c|c|c}
\hline $\begin{array}{c}\text { Estação do } \\
\text { ano }\end{array}$ & $\begin{array}{c}\text { Temperatura Máxima } \\
\left({ }^{\circ} \mathrm{C}\right) \text { - Ponto }\end{array}$ & $\begin{array}{c}\text { Temperatura Mínima } \\
\left({ }^{\circ} \mathrm{C}\right) \text { - Ponto }\end{array}$ & Amplitude $\left({ }^{\circ} \mathrm{C}\right)$ \\
\hline Outono & $27,81^{\circ} \mathrm{C}-\mathrm{P} 8 \mathrm{~T} 1$ & $26,19^{\circ} \mathrm{C}-\mathrm{P} 10 \mathrm{~T} 1$ & $1,62^{\circ} \mathrm{C}$ \\
\hline Inverno & $30,27^{\circ} \mathrm{C}-\mathrm{P} 8 \mathrm{~T} 1$ & $27,65^{\circ} \mathrm{C}-\mathrm{P} 10 \mathrm{~T} 1$ & $2,62^{\circ} \mathrm{C}$ \\
\hline Primavera & $32,01^{\circ} \mathrm{C}-\mathrm{P} 7 \mathrm{~T} 1$ & $30,36^{\circ} \mathrm{C}-\mathrm{P} 10 \mathrm{~T} 1$ & $1,65^{\circ} \mathrm{C}$ \\
\hline Verão & $28,80^{\circ} \mathrm{C}-\mathrm{P} 8 \mathrm{~T} 1$ & $27,13^{\circ} \mathrm{C}-\mathrm{P} 10 \mathrm{~T} 1$ & $1,67^{\circ} \mathrm{C}$ \\
\hline
\end{tabular}

análise da Umidade Relativa observa-se os maiores índices na estação do Verão característico na região por maior quantidade de precipitação, posteriormente a estação Outono, com característica de período de transição entre chuvoso e seco com índices intermediários de umidade (Figura 07).

Por conta das características de ocupação urbana entre os pontos 6 (P6T1) e 8 (P8T1), com predomínio uso de materiais impermeáveis e poucas massas de vegetação, pontualmente é uma região com índices baixos de umidade e consequente armazenamento de energia no meio, aumentando a temperatura do ar. 
Rev. Elet. em Gestão, Educação e Tecnologia Ambiental (e-ISSN: 2236-1170)

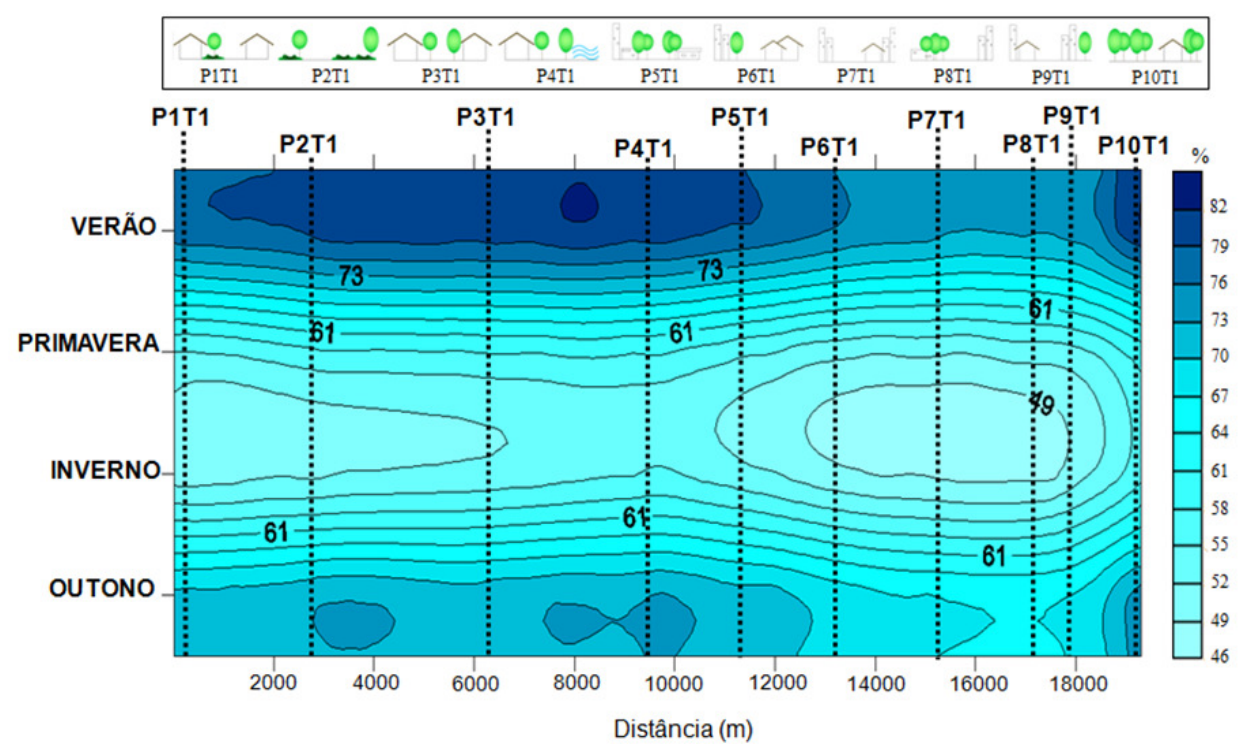

Figura 07 - Comportamento da Umidade Relativa - Transecto 1

\subsection{Transecto 2}

No Transecto 2, assim como o Transecto 1, observa-se maior magnitude da ilha de calor na estação da Primavera (Figura 08), apresentando a mesma tendência na variação de temperatura nas demais estações. As maiores temperaturas encontradas estão entre os pontos 2 (P2T2) e 6 (P6T2) justificado pela urbanização da área com grande ocupação do solo por revestimentos impermeáveis.

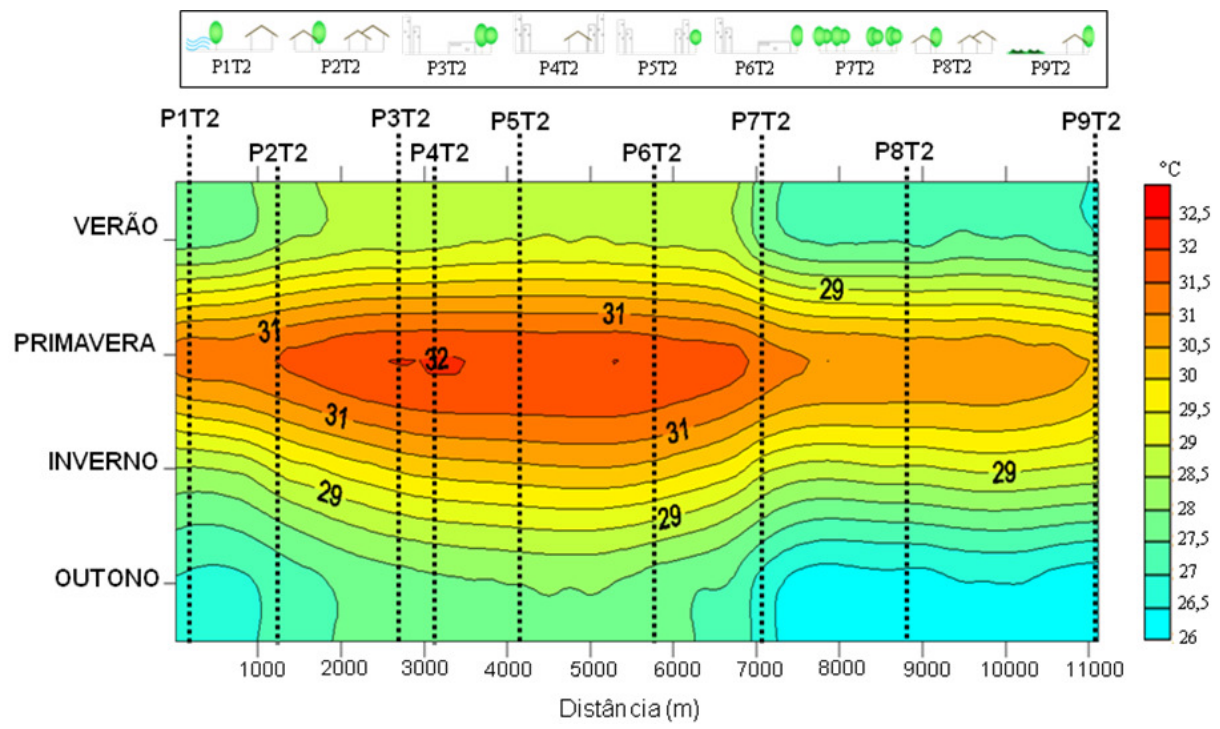

Figura 08 - Comportamento da Temperatura do Ar - Transecto 2

Observa-se que o Ponto 5 (P5T2) apresenta os maiores valores de Temperatura do Ar em três estações do ano, sendo que apenas na Primavera o Ponto 4 (P4T2) obteve a maior média de tempertaura do transecto. Os dois pontos estão localizados próximos aos cruzamentos de avenidas de grande fluxo de veículos da cidade - Av. Mato Grosso (P4T2) e Av. Miguel Sutil (P5T2) e possuem características de ocupação parecidas. 
Quanto as temperaturas mínimas, o Ponto 9 (P9T2) apresentou as menores médias em três estações do ano, enquanto que o Ponto 1 (P1T2) teve a menor média de temperatura no Inverno. Os dois pontos sofrem influência da umidade local proveniente do Rio Cuiabá em P1T2 e por vegetação remanscente em P9T2.

Tabela 03 - Temperatura Máxima e Mínima no Transecto 2

\begin{tabular}{c|c|c|c}
\hline $\begin{array}{c}\text { Estação do } \\
\text { ano }\end{array}$ & $\begin{array}{c}\text { Temperatura Máxima } \\
\left({ }^{\circ} \mathrm{C}\right)-\text { Ponto }\end{array}$ & $\begin{array}{c}\text { Temperatura Mínima } \\
\left({ }^{\circ} \mathrm{C}\right)-\text { Ponto }\end{array}$ & Amplitude $\left({ }^{\circ} \mathrm{C}\right)$ \\
\hline Outono & $27,26^{\circ} \mathrm{C}-\mathrm{P} 5 \mathrm{~T} 2$ & $25,44^{\circ} \mathrm{C}-\mathrm{P} 9 \mathrm{~T} 2$ & $1,82^{\circ} \mathrm{C}$ \\
\hline Inverno & $29,40^{\circ} \mathrm{C}-\mathrm{P} 5 \mathrm{~T} 2$ & $27,47^{\circ} \mathrm{C}-\mathrm{P} 1 \mathrm{~T} 2$ & $1,93^{\circ} \mathrm{C}$ \\
\hline Primavera & $31,27^{\circ} \mathrm{C}-\mathrm{P} 4 \mathrm{~T} 2$ & $29,74^{\circ} \mathrm{C}-\mathrm{P} 9 \mathrm{~T} 2$ & $1,53^{\circ} \mathrm{C}$ \\
\hline Verão & $28,45^{\circ} \mathrm{C}-\mathrm{P} 5 \mathrm{~T} 2$ & $26,54^{\circ} \mathrm{C}-\mathrm{P} 9 \mathrm{~T} 2$ & $1,91^{\circ} \mathrm{C}$ \\
\hline
\end{tabular}

Quanto a análise da Umidade Relativa (Figura 09), observa-se maior disponibilidade no início e final do Transecto, justificado pela proximidade do Rio Cuiabá do ponto 1 (P1T2) e pelo tipo de ocupação do solo com características de áreas periféricas com vegetação remanescente.

Na estação da Primavera e do Inverno, características na região pela baixa umidade do ar, a amplitude é menor.

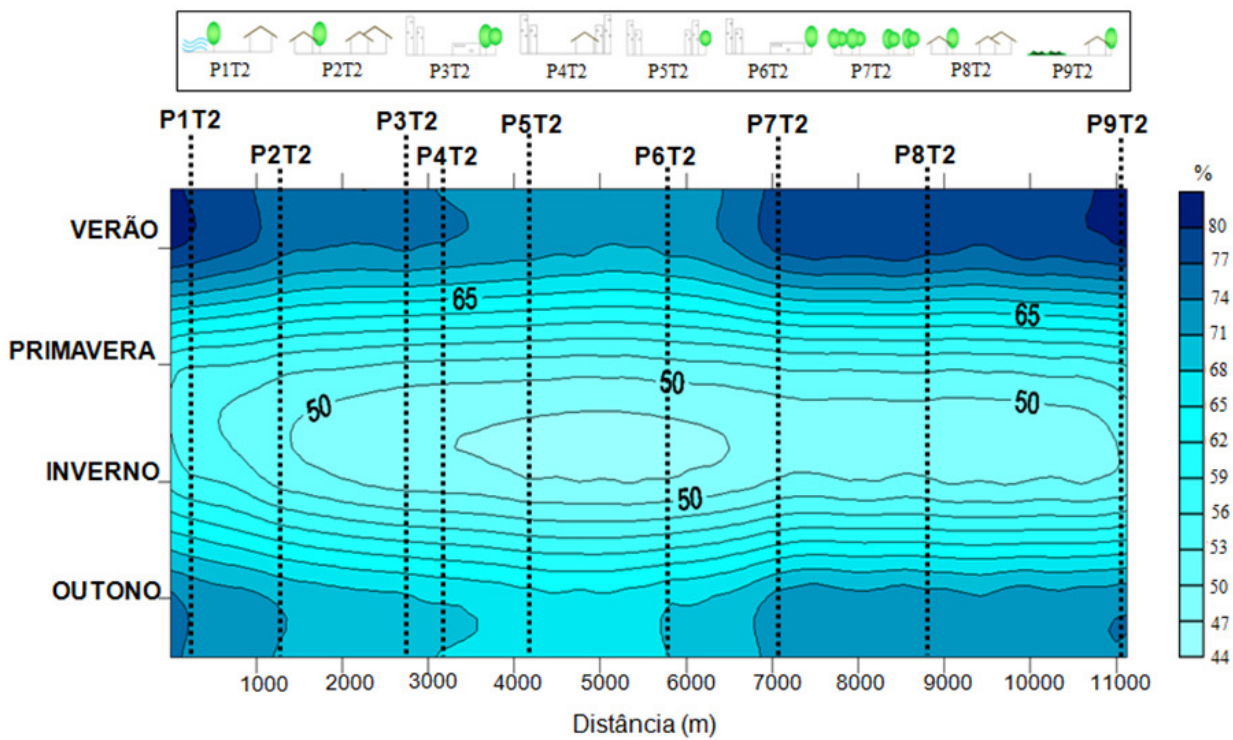

Figura 09 - Comportamento da Umidade Relativa - Transecto 2

De acordo com o dendrograma do Transecto 1 (Figura 10), considerando-se a distância marcada no ponto 5, pode-se observar a formação de 3 grandes grupos. 


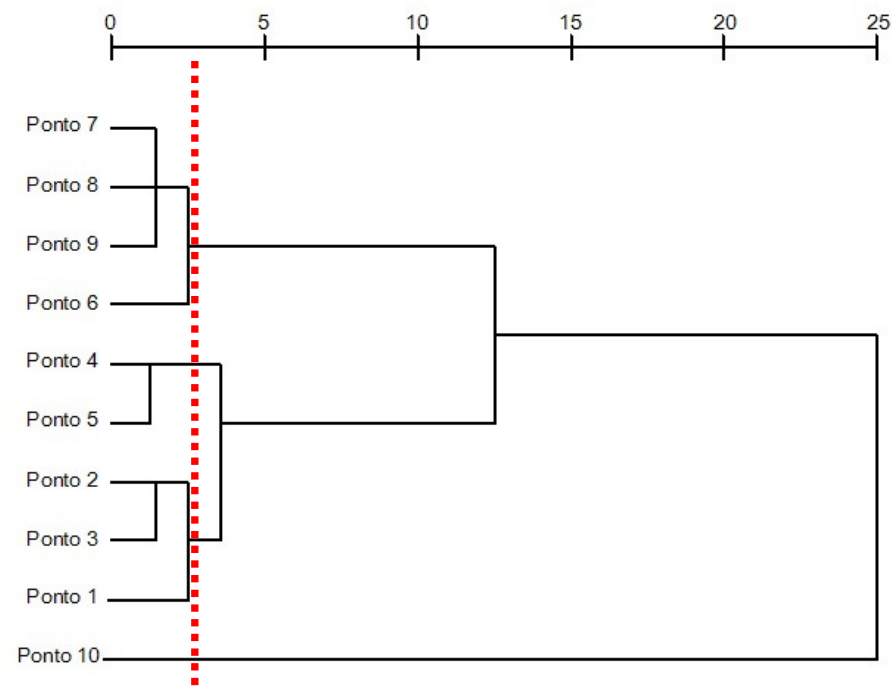

Figurā 10 - Dendrograma do pontos do Transecto 1

Tabela 04 - Grupo da similaridade dos pontos no Transecto 1

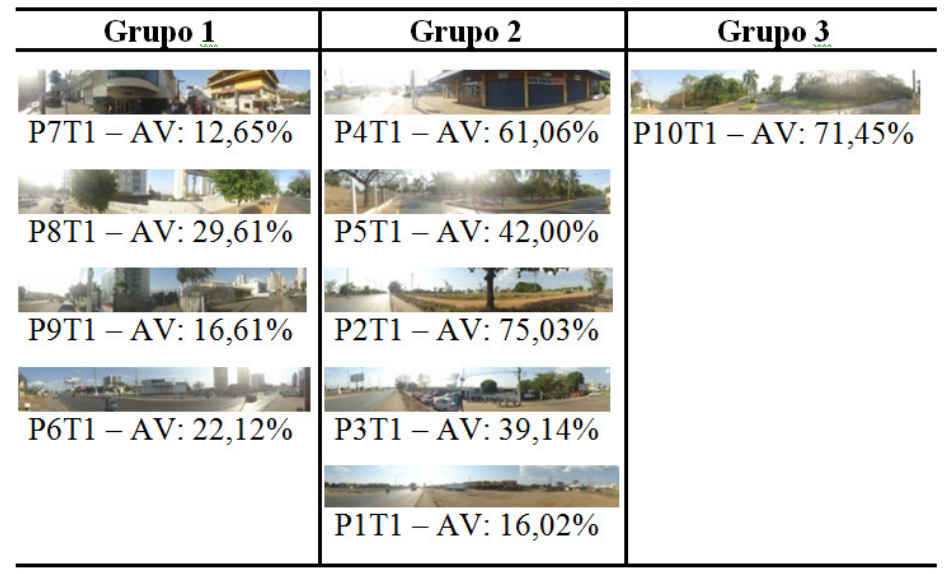

O primeiro grupo é formado pelos pontos com maior fluxo de veículos e pouca influência de vegetação e corpos d'água, com canyons urbanos consolidados. São pontos com ocupação do solo predominantemente comercial e com grandes áreas impermeabilizadas, com as menores porcentagens de área verde (AV) entre os pontos.

O segundo grupo apresenta características semelhantes com pouca rugosidade superficial, mas com influência do tráfego de veículos. A presença de arborização também é característica entre os pontos, sendo que o Ponto 4 ainda sofre influência do Rio Coxipó, aumentando a umidade no entorno imediato, enquanto que o Ponto 5, que possui maior semelhança com o Ponto 4, a alta umidade é proveniente da grande área arborizada. Observou-se que o Ponto 1 apresentou porcentagem de área verde característico do grupo $1-16,02 \%$, evidenciando-se que a menor quantidade de construções do entorno imediato influenciou as características climáticas locais.

O terceiro grupo é formado apenas pelo ponto 10 que está localizado próximo a um parque da cidade, apresentando como característica principal a maior quantidade de indivíduos arbóreos com porcentagem de área verde de $71,45 \%$. O local ainda apresenta pouco tráfego de 
veículos, diminuindo assim o calor antropogênico, e aumentando a influência da vegetação existente no ambiente.

De acordo com o dendrograma do Transecto 2 (Figura 11), considerando-se também a distância marcada no ponto 5, observou-se a formação de 4 grandes grupos.

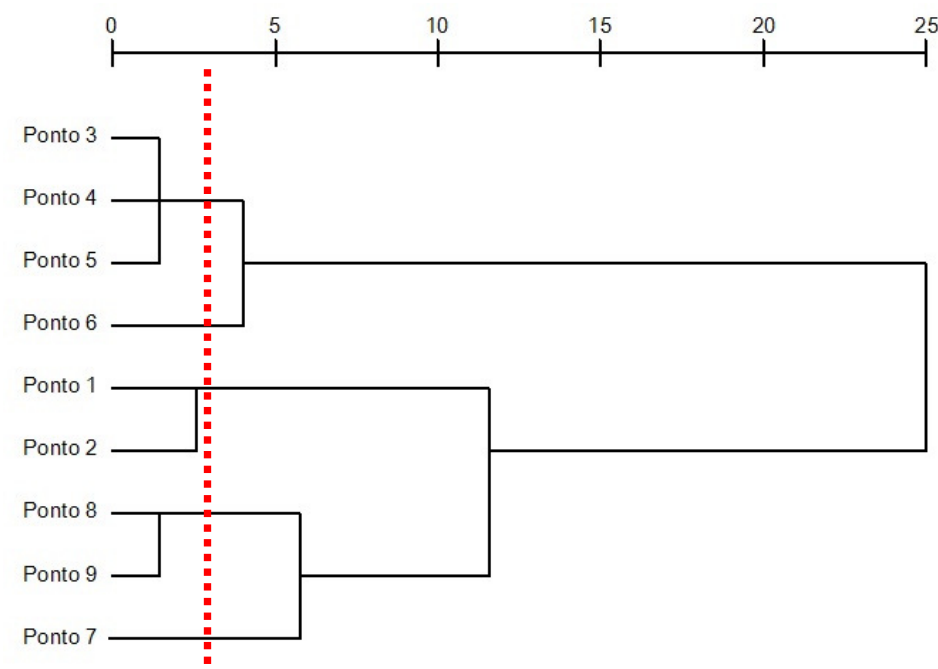

Figura 11 - Dendrograma do pontos do Transecto 2

Tabela 05 - Grupo da similaridade dos pontos no Transecto 2

\begin{tabular}{c|c|c|c}
\hline Grupo 1 & Grupo 2 & Grupo 3 & Grupo 4 \\
\hline P3T2 - AV: $26,64 \%$ & P1T2-AV: $40,06 \%$ & P8T2-AV: $18,15 \%$ & P7T2-AV: 77,17\% \\
\hline P4T2 - AV: 7,77\% & P2T2-AV: 14,94\% & P9T2-AV: $53,37 \%$ & \\
P5T2-AV: $13,85 \%$ & & & \\
P6T2-AV: $18,17 \%$ & & & \\
\hline
\end{tabular}

O primeiro grupo é formado pelos pontos localizados nas áreas mais urbanizadas do transecto, com fluxo de veículos intenso e grande impermeabilização do solo com as menores porcentagens de área verde (AV), além de possuir maior verticalização das edificações formando os canyons urbanos. Os pontos 3, 4 e 5 apresentam maiores semelhanças entre si, apresentando as mesmas características de ocupação do solo, sendo ponto 4 e 5 localizados nos cruzamentos de duas importantes vias de tráfego e o ponto $3 \mathrm{em}$ área central da cidade. 0 ponto 6 , apresenta particularidades em relação ao grupo, pois está também localizado em uma área de intensa trafegabilidade, próximo a um shopping da cidade, mas a largura da via é maior em relação aos outros pontos, diminuindo desta forma, o efeito do canyon urbano.

O segundo grupo é formado pelos pontos 1 e 2 caracterizado pela baixa verticalização das edificações na proximidade, apesar de estarem localizados em áreas próximas ao centro da cidade, o fluxo de veículos neste locais, principalmente no horário de medição, é inferior aos do primeiro grupo. Sofrem influência da umidade proveniente do Rio Cuiabá, principalmente o ponto 1 devido a proximidade ao mesmo, enquanto que o ponto 2 apesar de estar mais distante e 
Rev. Elet. em Gestão, Educação e Tecnologia Ambiental (e-ISSN: 2236-1170)

apresentar porcentagem de área verde característica do Grupo 1 -14,94\%, a configuração urbana entre os pontos facilita a influência da umidade, já que devido ao traçado da via e ausência de grandes obstáculos funcionando como corredores de vento com ar úmido.

No terceiro grupo estão os pontos 8 e 9 localizados em área periférica da cidade, sem influência de verticalização predial. Nestes pontos, a largura da rua diminui consideravelmente, sendo que no ponto 8 o fluxo de veículos e pessoas é maior devido a atrativos do entorno como um ginásio, quiosques de lanches rápidos, templos religiosos e maior ocupação do solo, além da menor quantidade de área verde comparando-se ao ponto 9. Este último está localizado em área de ocupação recente, com pouco fluxo de veículos e baixa circulação de pessoas, possui ainda grandes áreas vazias com vegetação rasteira.

O quarto grupo é formado pelo ponto 7, que assim como o ponto 10 do Transecto 1, está localizado próximo a um parque da cidade, sofrendo influência da massa de vegetação do local com porcentagem de área verde de $77,17 \%$. Nos horários iniciais e de término comercial ocorre um aumento no número de veículos trafegando na área, já que o local é corredor de tráfego do centro para bairros da periferia e vice/versa.

\section{CONCLUSÃO}

Os dados coletados nesta pesquisa evidenciaram que Cuiabá apresenta um perfil térmico que coincide com grande parte dos estudos realizados no período noturno, os quais registram na área mais densamente construída, um pico positivo de temperatura, comprovando-se a existência de ilha de calor na cidade.

Destaca-se que áreas sob influência de grandes massas de vegetação, apresentaram características próprias com microclima diferentes as outras áreas da cidade, contribuindo para formação de ilhas higrométricas, já que há uma contribuição na perda de energia para o meio e conseqüente diminuição nos valores de temperatura do ar e aumento da umidade relativa do ar, evidenciando-se a importância da implantação de parques urbanos em locais de clima semelhantes ao de Cuiabá.

A influência do fluxo de veículos nos ganhos de calor no meio é evidente, já que áreas com menor circulação de automóveis apresentaram climas mais agradáveis às áreas com mesmas características de ocupação do solo, mas com menor fluxo de veículos, e consequentemente menor calor antropogênico.

Deve-se ressaltar que este estudo irá contribuir no meio acadêmico e científico para diagnosticar eventuais mudanças no clima devido ao processo de crescimento de Cuiabá, que precisam ser considerados pelos planejadores para que sejam tomadas medidas que contribuam com a melhoria da qualidade ambiental e de vida da população.

\section{AGRADECIMENTOS}

Os autores agradecem a ELETROBRÁS e a CAPES pela ajuda e apoio financeiro no desenvolvimento da pesquisa.

\section{REFERÊNCIAS BIBLIOGRAFICAS}

ALVES, E. D. L. Ilha de Calor ou Ilha de Energia Térmica: um conceito aberto à discussão. 2010. Revista Espaço Acadêmico, n.110, p. 124-129. 
AMORIM, M. C. C. T. O clima urbano de Presidente Prudente/SP. 2000. 374 f. Tese (Doutorado em Geografia Física) - Faculdade de Filosofia, Letras e Ciências Humanas, Universidade de São Paulo, São Paulo.

ARAUJO, A. P.; ALEIXO, N. C. R.; MENEZES, B. B.; SOUZA, C. G.; RIVERO, C. A. V.; MONTEZANI, E.; BRAIDO, L. M. H.; TEODORO, P. H. M.; AMORIM, M. C. C. T. Ensaio Metodológico Sobre a Utilização de Transectos Móveis no Período Diurno em Presidente Prudente-SP. Revista Formação, 2008, v. 1, n.17, p. 77-95.

CUIABÁ. Prefeitura Municipal de Cuiabá. Instituto de Pesquisa e Desenvolvimento Urbano. Perfil socioeconômico de Cuiabá. 2009, Vol.II - Cuiabá: IPDU/ Instituto de Planejamento e Desenvolvimento Urbano. Cuiabá.

GARCÍA, F. F. Manual de climatologia aplicada: clima meio ambiente y planificación. 1996, Ed. Síntesis, Madri, p. 199-278.

MONTEIRO, C. A. F.; MENDONÇA, F. Clima Urbano: teoria e clima urbano. 2003, Ed.Contexto. São Paulo, p. 9-69.

OLIVEIRA, A. S. Influência da vegetação arbórea no microclima e uso de praças públicas. 2011, Cuiabá, 146f. Tese (Doutorado) - Programa de Pós-graduação em Física Ambiental, Universidade Federal de Mato Grosso.

OKE, T. R. The energetic basis of the urban heat island. Quarterly Journal of the Royal Meteorological Society, 1982, v.108, n. 455, p. I-24.

Identificação dos Autores:

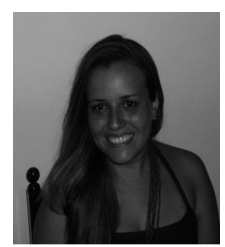

Flávia Maria de Moura Santos

Graduação em Arquitetura e Urbanismo pela Universidade Federal de Mato Grosso/ UFMT; Professora Efetiva do Departamento de Arquitetura e Urbanismo/ UFMT;

Doutora pelo Programa de Pós Graduação em Física Ambiental/ PPGFA/ UFMT, Linha de Pesquisa: Análise Microclimáticas em Sistemas Urbanos, E-mail: flavia_mms@hotmail.com 
Rev. Elet. em Gestão, Educação e Tecnologia Ambiental (e-ISSN: 2236-1170)

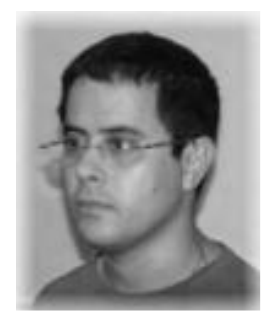

Carlo Ralph De Musis

Graduação em Engenharia Civil pela Universidade Federal de Mato Grosso/ UFMT;

Professor Efetivo da Universidade de Cuiabá/ UNIC;

Professor do Programa de Pós-Graduação em Física Ambiental, Linha de Pesquisa: Análise Microclimáticas em Sistemas Urbanos, E-mail: carlo.demusis@gmail.com

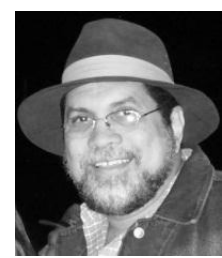

José de Souza Nogueira

Graduação em Licenciatura Plena em Física pela Universidade Federal de Mato Grosso/ UFMT;

Professor Efetivo do Instituto de Física/ UFMT;

Professor do Programa de Pós-Graduação em Física Ambiental e Coordenador do Programa de Pós-Graduação em Física Ambiental em nível de Mestrado e Doutorado, E-mail: nogueira@ufmt.br

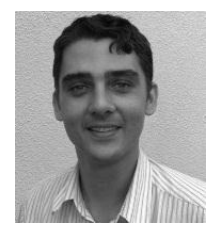

\section{Osvaldo Borges Pinto Júnior}

Graduação em Ciências Biológicas pela Universidade Estadual de Mato Grosso/ UNEMAT;

Professor Efetivo da Universidade de Cuiabá/ UNIC;

Professor do Programa de Pós Graduação em Física Ambiental/ PPGFA/ UFMT, Linha de Pesquisa: Análise Microclimática em Sistemas Urbanos, E-mail: osvaldo.borges@gmail.com

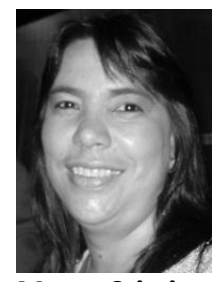

Marta Cristina de Jesus Albuquerque Nogueira

Graduação em Engenharia Civil pela Universidade Federal de Mato Grosso/ UFMT;

Professor Efetiva do Departamento de Arquitetura e Urbanismo/ UFMT;

Professora do Programa de Pós Graduação em Física Ambiental/ PPGFA/ UFMT, Linha de Pesquisa: Análise

Microclimáticas em Sistemas Urbanos, E-mail: mcjanp@gmail.com 